\title{
Neurophysiological and neuroimaging changes (crossed cerebrocerebellar atrophy) after prolonged non-convulsive status epilepticus
}

Alterações de neuroimagem e de neurofisiologia após estado de mal epiléptico não-convulsivo

Jivago S. Sabatini', Fabrício Stewan Feltrin², Márcio Andriani Rahal', Luiz César Lopes ${ }^{1}$, Marcelo Rezende Young Blood ${ }^{1}$, Leilane Hoffmann Nogueira ${ }^{1}$, Diogo Lago Pinheiro ${ }^{2}$, Carlos Henrique Ferreira Camargo ${ }^{1}$

A 33-year-old female patient suffering from epilepsy since the age of seven years (Figure 1) presented with left-sided hemiparesis following non-convulsive status epilepticus (NCSE) (Figure 2). Neuroimaging showed a reduction in volume of the right cerebral hemisphere and left cerebellar hemisphere (Figure 3). EEG showed asymmetry with right hemispheric slowing (Figure 4).
NCSE can have deleterious effects on the CNS because of neuronal death after 30 to 60 minutes of continuous convulsive activity ${ }^{1,2}$. Following an episode of NCSE, 10 to $50 \%$ of patients present with incapacitating neurological deficit ${ }^{3}$. Cranial MRI may show a persistent hyperintense lesion in T2- or diffusion-weighted images ${ }^{4,5}$.
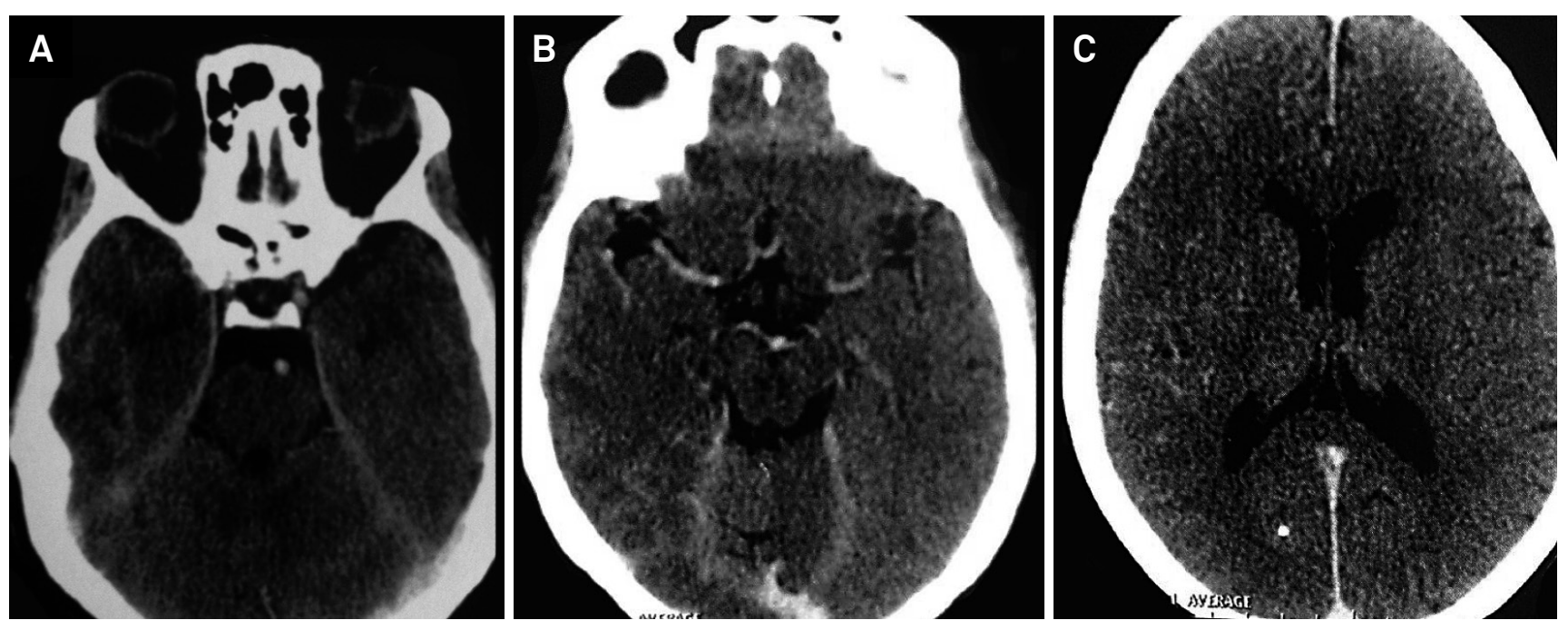

Figure 1. Cranial computed tomography before the patient was admitted to hospital due to non-convulsive status epilepticus (January 2015).

\footnotetext{
'Universidade Estadual de Ponta Grossa, Hospital Universitário, Serviço de Neurologia, Ponta Grossa PR, Brazil; ${ }^{2}$ Universidade Estadual de Ponta Grossa, Hospital Universitário, Unidade de Radiologia, Ponta Grossa PR, Brazil. Correspondence: Carlos Henrique Ferreira Camargo; Departamento de Medicina, UEPG; Rua Carlos Cavalcanti, 4748; $84030-900$ Ponta Grossa PR, Brasil; E-mail:chcamargo@uol.com.br

Conflict of interest: There is no conflict of interest to declare.

Received 13 July 2015; Received in final form 14 August 2015; Accepted 04 September 2015.
} 

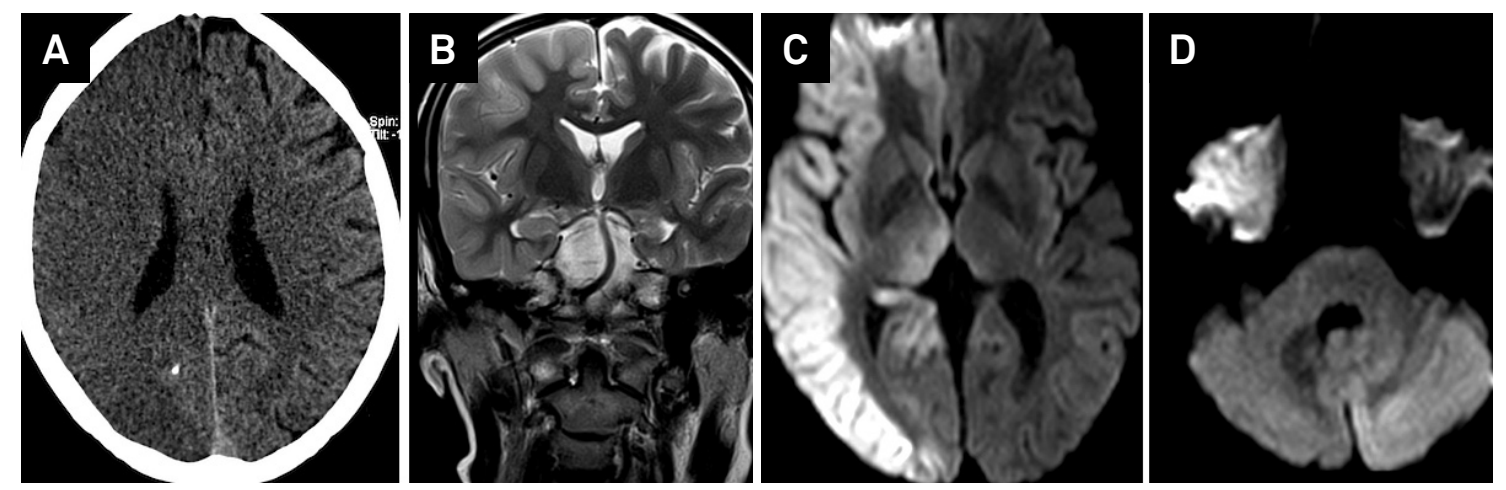

(A) Computed tomography performed without intravenous contrast on the day of the episode showing swelling and cortical edema in the right brain hemisphere and left cerebellar hemisphere as well as calcification of the parietal region of the right cerebral hemisphere. (B) Coronal FLAIR MRI image showing cortical edema in the right cerebral hemisphere. Left hippocampal formation with reduced volume and hyperintense signal. (C) and (D) Diffusion-weighted axial MRI images showing diffusion restriction in the regions mentioned above, indicating cytotoxic edema.

Figure 2. Brain images (April 2015) after the patient was admitted to hospital.
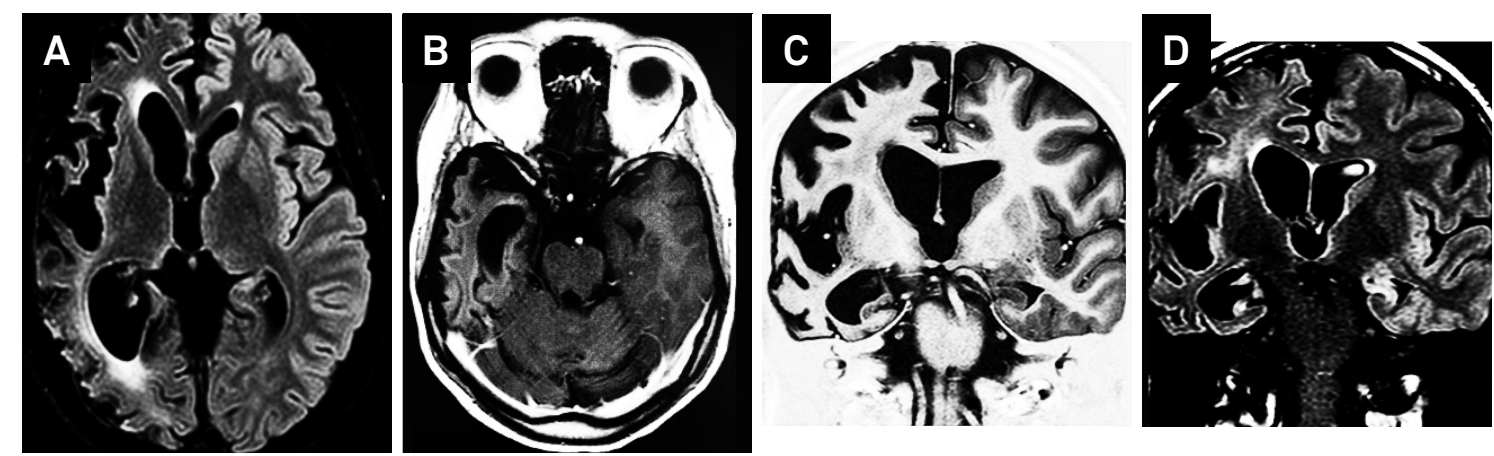

(A) Axial FLAIR MRI image showing marked atrophy of the right brain hemisphere and discrete signal hyperintensity in the white matter caused by Wallerian degeneration. T2-weighted (B) Axial T1-weighted MRI MRI image showing marked atrophy of the right brain hemisphere and left cerebellum (C) MRI images showing cortical thinning in the right cerebral hemisphere more clearly. (D) Coronal FLAIR-weighted MRI images showing a marked reduction in volume and an abnormal signal in both hippocampal formations.

Figure 3. Brain MRI after the patient was admitted to hospital for non-convulsive status epilepticus (June 2015)

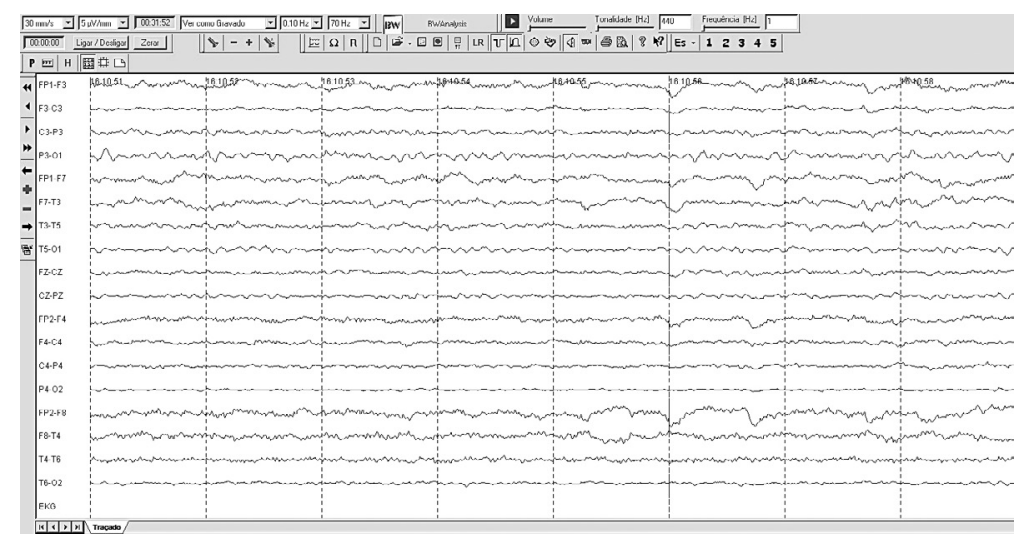

Figure 4. EEG performed in May 2015 showing asymmetry due to slowing of the right brain hemisphere (a sequela of prolonged non-convulsive status epilepticus).

\section{References}

1. Fountain NB, Lothman EW. Pathophysiology of status epilepticus.J Clin Neurophysiol. 1995;12(4):326-42.

2. Chapman MG, Smith M, Hirsch NP. Status epilepticus. Anaesthesia. 2001;56(7):648-59. doi:10.1046/j.1365-2044.2001.02115.x

3. Cooper AD, Britton JW, Rabinstein AA. Functional and cognitive outcome in prolonged refractory status epilepticus. Arch Neurol. 2009;66(12):1505-9. doi:10.1001/archneurol.2009.273
4. Donaire A, Carreno M, Gómez B, Fossas P, Bargalló N, Agudo R et al. Cortical laminar necrosis related to prolonged focal status epilepticus.J Neurol Neurosurg Psychiatry. 2006;77(1):104-6. doi:10.1136/jnnp.2004.058701

5. Parmar H, Lim SH, Tan NC, Lim CC. Acute symptomatic seizures and hippocampus damage: DWI and MRS findings. Neurology. 2006;66(11):1732-5. doi:10.1212/01.wnl.0000218207.18707.f4 